\title{
Drenar ou não nas laparotomias genitaes?
}

\section{PROF. NICOLAU DE MORAES BARROS}

Eis una questão interessante e que se mantém de permanencia na ordem do dia. Renhida vae a controversia por ella suscitada e, mau grado o muito que se tem escripto e discutido, a despeito de bem orientados estudos clinicos e experimentaes, de uma observação cuidada e numerosos dados estatisticos ainda não foi possivel esclarecel-a por completo, reduzindo-a a uma formula simples e suggestiva que servisse de directriz á conducta cirurgica.

E' ciassico em cirurgia pelvico-abdominal o recurso á drenagem, sempre que sé presuma uma contaminação peritoneal ou que circumstancias occorram conducentes a uma possivel ou provavel peritonite. D’ahi a enumeração de uma longa série de opportunidades para drenar, equivalentes a outras tanta ${ }_{S}$ indicações mais ou menos imperativas A observação, entretanto, aos poucos se encarregou de as restringir. demonstrando a sua absoluta superfluidade em elevada porcentagem de casos.

Vem já de 20 annos a reacção methodisada contra taes exageros. Iniciada na America do Norte, com Kelly e Clarck, ella reper-

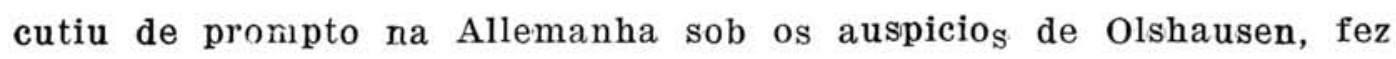
rapido proselytismo, conquistou dedicações, impoz-se com tal força, que hoje formam legião os adversarios intransigentes da drenagem ao lado de outros não menos systematicos e estremados que se mantêm fiei ${ }_{S}$ ao tradicionalismo, apegados á velha rotina, insensiveis a argumentos e provas, obsecados que estão pelo espantalho da peritonite, caso prescindam dessa valvula garantidora que é o dreno.

Nem por sombr^ nos move o intuito de tomar posição na contenda, muito menos a velleidade de pôr termo ao litigio. $O$ que cogitamos com estas descosidas phrases é, tão sómente contribuir, er escala minima, para o esclarecimento do assumpto, trazendo a publico a escassa observação colhida na enfermaria de Gynecologia da Santa Casa, a qual, se para outra cousa não servir, talvez tenha : virtude de vencer algumas resistencias bem intencionadas em nossc meio, desintimidando-as, encorajando a restriç̧ão da drenagem f recrutando uns poucos adeptos á pratica de abstencionismo moderado. 
Em nosso meio hospitalar drena-se tão raramente que, quas se póde affirmar, estar alli abolido esse recurso cirurgico. Meze e mezes se passam, dezenas e dezenas de laparatomias se fazem, sem que se cogite siquer da collocação de um tubo. E ainda está para ser regictada a vez em que dessa abstenção resultou grave damno para a paciente. Pensamos não exagerar affirmando que em 3 annos de actividade com um numero approximado de 260 la parotomias, ainda não se consumiu alli um metro de borracha!

Consideremos, resumidamente, as indicações. Sentencia a escola classica que se deve drenar: 1.o - quando no decurso da laparatomia, houver estravasamento de productos septicos na cavida* de peritoneal (pús, conteúdo intestinal, sanie ou detrictos tumoraes infectados); 2.0 - quando do acto cirurgico resulte larga ferida pelvica desnuda de peritoneo; 3.o quando fôr impossivel uma he mostase perfeita; 4.0 quando, sendo incompleta a exerese cirurgica, i uem restos adherentes ás visceras (residuos inflammatorios, fra gmentos de capsula, parede do hematocele, etc.); 5.o - finalmente, quarde se verifique lesão da bexiga ou uretere. Nesse conjunctc de opportunidades, prosegue, occorrem circumstancias favora-

; á actividade infectante de germens eventualmente introduzidona cavidade peritoneal e deve-se drenar para obviar a peritonite $\mathrm{Na}$ formula deste conceito não collaboraram, por certo esquecido. ou desprezados, factores de grande peso, e transcendencia, tae $e_{S}$ co mo: as energias defensivas do peritoneo, o aperfeiçoamento da technica operatoria e o empregc generalizado do banho de ether no epilogo de cada laparotomia. Ei S $_{\mathrm{S}}$ porque não costumamos drenar na maioria daquellas hypotheses, quer se apresentem isoladas, quer mesmo coincidam varias dellas simultaneas na mesma doente.

Duas palavras sobre cada item. No primeiro - derrame de pús, contcúdo irtestinal ou sanie tumoral faz-se mistér distinguir os casos. Nas annexites suppuradas, o tratamento cirurgico ê um methodo de excepçio pela sua manifesta inferioridade ao tratameito conservádor, resolutivo. Quando se tenha de operar deve-se fazel-o a frio, algumas semanas, pelo menos, depois que a curva th mometrica se normalizou, em época, portanto, em que o agente etiologico, succumbindo á acção das proprias toxinas, se tornou inoffensivo. Nestas condições, para que drenar?

Accresce que na maioria dos casos, o germen activo é o diplococco de Neisser, tão pouco aggressivo para o peritoneo que Bumm se permittiu affirmar nunca ter sido elle causador da per:tonite mortal. De sorte que, mesmo na vigencia de gonococco com: virulencia arenas attenuada, a drenagem preventiva é inutil. Temos operado volumosos pyosalpinx duplos com abundante extrava- 
são te pus, sem que, até o presente, num só caso que fosse, sobreviessem complicações peritoneaes sérias. Fechamos o ventre por completo e ainda não nos arrependemos.

Se a contaminação é de origem intestinal, a conducta terá que se amoldar ás circumistancias. Ou a lesão do intestino foi constatada no momento preciso em que occorreu, não houve extravasamento visivei e a roparação se fez com boa technica - e não se drena. ou admitte-se derrame septico na cavidade ou não se confia, por difficuldadez technicas, na occlusão feita - e a drenagem se impóe.

Em recente observação em nosso serviço com lesão de uma alça iliaca e evicente derrame de fezes, fez-se a drenagem pela betesga de Douglas, mas aconteceu que ao cabo de oito horas a doente retirou o tubo num gesto impensado e. tudo correu em branca narem.

A sanie ou detricto de tumor esphacelado reclamam a drenagem. Seja na operação de Wertheim por carcinoma do collo, seja na hysterectomia pọr fibroma ou sarcoma infectado, se não ha cer teza de que o peritoneo foi preservado, drene-se.

No que respeita aos itens - 2.0, 3.0 e 4.0 - respectivamente peritonização deficiente, hemostase imperfeita e restos de ca.psula, não costumamos drenar ainda que taes circumstancias con corram associadas no mesmo caso. De algumas observações nos recordamos, em que, ás tres indicações acima se juntava ainda o derrame de pus, aggravando a situação e escurecendo o prognostico Infundado receio! $O$ dreno não fez falta.

Por hemostase imperfeita se entende aquella em que na loja deixada pelo tumor e desnuda de peritono, o sangue brota aqui alli em fios tenuissimos, zombando dos recursos hemostaticos communs por inapplicaveis ou insufficientes. Em taes casos, a pressão intra-abdominal restabelecida com o fechamento do ventre se encarrega da hesmostase, cumprindo apenas, ao desfazer o Trendelenburg, agir de maneira que o grande epiploon antecipe as alças intestinaes na occupação da loja vasia, afim de que com elle e nã com estas se constituam as novas adherencias.

Na hypothese da lesão da bexiga ou do uretere, a conducta teT que inspirar nas condiçõez de cada caso. De regra, lesão da bexiga na sua porção alta, bem suturada, se satísfaz com a sonc de demora, ró se justificando o dreno nos casos de fechamento inseguro do orgåo, seja pela séde da lesão, de difficil accesso á technica, seja pela sua extensão, quando larga reseção da parede * foz necessaria (propagação cancerosa) Seç̧ão do uretere e mesmo reparada incontinenti pela anastomose das extremidades ou $p^{-}$ la implantação vesical, reclama dreno, pois é intuitiva a precisã 
de um escoadouro para a urina, caso não vingue a sutura reparadora.

Mas aqui como alhures, nas poucas vezes em que a drenagem se justifica, ella tem que ser vaginal, pois consideramos o methodo abdominal com o tubo no angulo inferior da ferida, uma pratica insufficiente e destituida de senso cirurgico.

E' pelo menos, uma imperfeição technica, que, sobre promover adherencias intestinaes e, possivelmente, a formação de fistulas tstercoraes, prolonga o periodo post-operatorio, compromette solidez da cicatriz e predispõe a eventrações. Si, em compensação, drenasse de verdade e garantisse contra a peritonite?!

Mas é isso precisamente que não acontece. Nos livros, revistas e discussões das sociedades scientificas se encontra farta documentação nesse sentido. Assim, pois, nas poucas veze ${ }_{S}$ em que drenamos, fazemol-o com tubo de borracha, calibroso e consistente, introduzido na vagina de dentro para fóra, através da betesga do Douglas.

Na immensa maioria dos casos, não drenamos mas não pres. cindimos, entretanto da desinfecção a ether, pratica na qual, talvez, resida, em grande parte, o segredo de nossos successos.

Para remate, alguns dados numericos. No decurso destes tres ultimos annos foram praticadas em nosso serviço cêrca de 256 la. parotomias, reclamadas pelas mais variadas gynecopathias, com 6 drenagens $(3,12$ o|o $)$ e 9 mortes $(3,51$ o|o $)$ Entre as fallecida figuram: 3 operações de Wertheim, por carcinoma do collo; 3 hys terectomias por fibrsma (uma das quaes por syncope anesthesica) 1 por tuberculose genital, 1 por prenhez tubaria e 1 por annexite

$A_{S} 8$ drenagen $_{S}$ foram indicadas: 3 por lesão do intestino, por carcinoma do collo e apenas 2 por annexite com derrame de pús. Daquelle total de 256 laparotomias, se destacam 108 indicadas por annexites - unilateral, umas, bilateral, outras, e associadas a retroversão, fibroma e appendicite, ainda outras.

Pois bem, em 42 desses 108 casos de annexite, houve extravasamento mais ou menos abundante de pús, aggravado, na maioria dellas, com heınostase imperfeita, peritonização deficiente e permanencia de restos tumoraes; com duas drenagens tão sómente e um unico caso de morte!

0 que quer dizer que apenas em 4,78 olo dos caso em que $_{\mathrm{S}}$ concorrerar: simultaneamente varias indicações para a drenagem, se lançou mão desse recurso, não excedendo, nelles, a mortalidad. (i) 2,4 o| 0 !

Estes poucos algarismos pertinentes, embora, a um escasso material, são, por si sós, bastante eloquentess e dispensam commentarios. 